\title{
Ética e direitos humanos na e pela pesquisa e extensão universitárias
}

Fernanda Spanier Amador ${ }^{\star}$

\begin{abstract}
Resumo
Neste artigo discuto a ética e os direitos humanos na e pela pesquisa e extensão universitárias, transversalizando os conceitos de tempo e de subjetividade, sobretudo a partir das contribuições de Deleuze, Guattari e Foucault. Abordando a ética, os direitos humanos, a produção de conhecimento e a vida em sua instigante indiscernibilidade, convido a refletir sobre a assunção de uma postura, enquanto pesquisadores e extensionistas, em devir, ou seja, cedendo lugar à experimentação e acionando a diferença. Discuto sobre o tema no plano das epistemologias propondo a promoção da ética e dos direitos humanos na esfera mesma da produção de conhecimento.
\end{abstract}

Palavras-Chave: Ética. Direitos humanos. Pesquisa. Extensão.

\section{Human ethics and rights in the university research and extension}

\begin{abstract}
In this article ethics and the human rights are discussed in and through university research, crossing the concepts of time and subjectivity, following the theoretical references of Deleuze, Guattari and Foucault. Approaching ethics, human rights, "knowledge production" and life as intertwined notions, it proposes the possibility of the attitude of "researchers to be", which involves the possibility of working with experimentation and "difference". The discussion is carried out in the plan of epistemologies and proposes the promotion of ethics and human rights in the same sphere of "knowledge production".
\end{abstract}

Keywords: Ethic. Human rights. Research. Extension.

\footnotetext{
^ Psicóloga, Mestre em Psicologia Social e da Personalidade (PUCRS) e docente do Departamento de Psicologia da Universidade de Santa Cruz do Sul (UNISC).

E-mail: feamador@uol.com.br
} 
[...] faça rizoma e não raiz, nunca plante! Não semeie, pique! Não seja nem uno nem múltiplo, seja multiplicidades! Faça a linha e nunca o ponto! A velocidade transforma o ponto em linha! Seja rápido, mesmo parado! Linha de chance, jogo de cintura, linha de fuga. Nunca suscite um General em você! Nunca idéias justas, justo uma idéia [...]. Tenha idéias curtas. Faça mapas, nunca fotos nem desenhos. Seja a Pantera Corde-Rosa e que vossos amores sejam como a vespa e a orquídea [...] (DELEUZE E GUATTARI, 1995, p. 15).

Abordar o tema da ética e dos direitos humanos na pesquisa e na extensão universitárias é uma tarefa, além de necessária, instigante e complexa. Concentrado nos métodos de produção de conhecimento, tal debate, contudo, parece conter uma esfera ainda pouco discutida, sobretudo no campo das Ciências Humanas e Sociais: refiro-me aos efeitos da pesquisa e da extensão, essas consideradas enquanto práticas e vetores de produção subjetiva, cuja implicação do ponto de vista do respeito e da luta pelos direitos humanos supera o âmbito dos modos operacionais, situando-se no plano das epistemologias.

Assim, tal problematização, que aparece indissociada da reflexão ética, implica uma ultrapassagem: transversalizar o debate sobre procedimentos recomendáveis ou não durante o desenvolvimento de pesquisas e de projetos de extensão, com uma discussão paradigmática no campo da ciência que nos permita, até mesmo, renunciar a um certo estatuto científico que tão violentamente, por vezes, suplanta a força mesma da vida enfraquecendo a defesa e a promoção da ética e dos direitos humanos na esfera da produção de conhecimento.

Para tanto, os conceitos de "tempo" e "subjetividade" em Deleuze (1988, 1998, 2002) e em Deleuze e Guattari (1995), possibilitando pensar a questão pela via de uma "Ética da Vida", aparecem como férteis ferramentas para a problematização do discurso que se tem forjado sobre ética na pesquisa, sob o título de Bioética. ${ }^{1}$

Pensar pela transversalização do tempo e da subjetividade permite a problematização das noções de individualidade e de universalidade, tão caras ao debate da ética e dos direitos humanos, desdobrando a noção de humano e de humanidade. Assim, mais do que falar em "Ética de fronteira e/ou cotidiana", detenho-me em uma Ética fronteiriça, uma ética que se opera num estado complicado em que começo e fim fazem parte simultânea e incessantemente do fluxo da vida.

Falo, então, de uma Ética da conexão, ${ }^{2}$ conforme propõe (SANT'ANNA, 2001), para quem uma tal ética exige, além de um certo discurso científico e de um programa político de governo, poder integrar-se ao curso ordinário da vida, o que implica, em última análise, tomar os seres vivos e os humanos como em constituição, tendo como princípio as conexões que os constituem ao longo da vida para, a partir daí, fazer frente a uma moral da dominação. 
Assim, é nessa direção que discorro sobre o tema ao longo deste texto. Abordando a ética, os direitos humanos, a produção de conhecimento e a vida em sua instigante indiscernibilidade, dirijo meu olhar aos modos de conexão com nossos campos de pesquisa e extensão para, desde aí, promover a ética e os direitos humanos.

Ultrapassando, portanto, uma discussão no âmbito dos procedimentos instituídos pelos Comitês de Ética, convido a refletir sobre a assunção de uma postura "nômade" e "errática", enquanto pesquisadores e extensionistas, por crer que aí, e justamente aí, é possível potencializar o enfrentamento a toda e qualquer tentativa de dominação. Falo de algo como tornar-se artífice da criação, justamente pela conexão com as não-formas, com os não-estratos, com as intensidades, com a vida.

\section{Sobre TEMPo, SUBJETIVIDAdE E ÉTICA}

Pensar o tempo como trama, eis a proposta de Deleuze (1988, 1998, 2002): tempo duração de forças, de intensidades e não de formas. Diferentemente da noção de tempo cronológico, sucedendo-se em fases e etapas, o autor propõe pensarmos algo como um tempo crônico, isto é, um tempo como coexistência virtual, cujo signo que o desdobra é a diferença, a multiplicidade. Potencializada pela lógica rizomática, ${ }^{3}$ tal concepção tem como princípio que o tempo contém uma infinidade de mundos, que causa e efeito são erráticos, que não há ordem, pontos ou origens, e que os estados intensivos substituem a topologia.

Também denominados de platôs, tais estados intensivos dão forma e extensão a um rizoma, o que confere a este último um caráter de velocidade e de conjunção que perturba a dimensão do Ser. Assim, Ser e Tempo são pensados como um meio, sem fim nem começo, sem reconciliação de um sentido pressuposto (PELBART, 1998).

No rompimento com uma perspectiva atomista, a subjetividade, então, passa a ser concebida enquanto estrutura virtual, isto é, uma trama, assim como o tempo, de virtualidades que só se atualizam por diferenciação, potencializando a problematização da subjetividade considerada enquanto interioridade privativa.

Para Pál Pelbart (1998, p. 5), a partir de Deleuze, a subjetividade apresenta-se como "seleção, subtração, preensão parcial, ação retardada, indeterminação, imprevisibilidade, curvamento do universo ao seu redor, contrariamente ao átomo [...]". Isso porque o tempo é tomado como um todo aberto que não pára de mudar de natureza a cada instante.

Desse modo, somos nós que habitamos o tempo e não o inverso, o que significa dizer que habitamos a cisão, já que é por ela que o tempo se funda. Ou seja, somente existindo a duração pela diferença, nós somos interiores àquilo que multiplicamos, que desdobramos, que (des)envolvemos. 
Para Deleuze, a partir das elaborações de Foucault:

A subjetividade pode então ser definida como uma modalidade de inflexão das forças do Fora, ${ }^{4}$ através da qual cria-se um interior. Interior que encerra dentro de si nada mais que o Fora, com suas partículas desaceleradas segundo um ritmo próprio e uma velocidade específica. A subjetividade não será uma interioridade fechada sobre si mesma e contraposta à margem que lhe é exterior, feito uma cápsula hermética flutuando num Fora indeterminado. Ela será uma inflexão do próprio Fora, uma dobra do Fora (DELEUZE, 1998, p. 135).

Desse modo, interessam a Deleuze o campo das singularidades impessoais e pré-individuais e os processos de individuação, em relação aos quais contribui Simondon (1964). Para o autor, que contesta uma substancialização do sujeito, o ser transborda o indivíduo e não se esgota nele. Assim, nós não apenas interiorizamos o que vem de fora, assimilando-o, mas também condensamos o tempo que sucede, consistindo a individuação num desdobramento do Ser, pelo qual este se defasa em relação a si mesmo. Em outras palavras, se diferencia de si.

Tal diferenciação ou singularização, pelo fato de o Ser constituir uma dobra de um não-ser, de um extra-ser, efetiva-se justamente remetendo-se ao impessoal: lugar das forças de todos e de ninguém. Por essa razão, todo Ser se torna um efeito de um agenciamento coletivo.

Contudo, acrescenta Pál Pelbart (1998, p. 55):

Se por um lado o sujeito se constitui na adjacência de uma cisão, de um desdobramento, que são também [...] atualizações de um virtual, [...] segundo Deleuze, o sujeito é constituído igualmente como que por um movimento inverso, por um dobramento, no sentido em que o fora, ao dobrar-se, cria uma interioridade.

Assim, por dobra e desdobra, constitui-se o si que já não mais é possível pensar fora de um raciocínio processual, pois a estrutura é diferenciada, contendo elementos diferenciais num agito intravirtual e indiferenciado, no sentido de que ainda está por se atualizar. A vida, então, só existe diferenciando-se de si, e o indivíduo, individuando-se a si mesmo.

Eis a vida e a criação fundindo-se num paradigma ético-estético, uma vez que, como prerrogativa da ética, temos a busca do impedimento de tudo aquilo que nos transforme em coisa manipulada e usada pelos outros, afirmando nosso direito à diferença (CHAUÍ, 1995; SANT'ANNA, 2001).

Entendendo a necessidade de afirmação da vida como um processo, no qual cada ser não é nem mais nem menos do que uma dobra do tecido da vida, Sant'Anna (2001, p. 99) propõe "relacionar forças, potencializá-las, ampliar suas ressonâncias, realçando ao mesmo tempo o indivíduo e o coletivo, o humano e o não humano, não para colocá-los acima da vida, mas dentro dela". 
Assim, pensando sob a perspectiva de uma "Ética dos encontros", a autora, tangenciando a dimensão do tempo como trama de virtualidades, fala de uma ética imbricada à aceitação do devir ${ }^{5}$ e ao reconhecimento da potência humana para diferir.

Trata-se de uma ética conectada e dando passagem à vida, a um plano de imanência que não existe em algo, que não é imanência a algo, nem depende de um objeto ou pertence a um sujeito (DELEUZE, 2002), pois se refere a um plano infrapessoal ou impessoal. Trata-se de ética dos encontros, pela qual a vida se vê potencializada e não limitada, desfazendo-se os limites definitórios das correspondências.

\section{Direitos humanos: UMA (DES)Dobra da ÉTICA}

Considerar os direitos humanos como um desdobramento da ética significa, de modo direto e evidente, falar em direito à vida. Vida não necessariamente territorializada nem substancializada em ninguém. Vida impessoal que se singulariza e acontece em "uma" vida.

Não obstante, perspectivas essencialistas e binarizantes ainda produzem contrastes nesse campo de debates. Trata-se de contrastes que se referem aos próprios elementos históricos que precipitaram nossa noção de direitos humanos: as lutas travadas pela burguesia européia contra o absolutismo, estando desde seu início marcadas pelos princípios da individualidade e da universalidade, fundamentos esses que aparecem indissociáveis da noção de propriedade privada e da conseqüente distinção entre direito público e direito privado. E, ainda, se referem a contrastes que se relacionam à polaridade entre os domínios dos direitos civis e políticos e os direitos econômicos e sociais, fortalecida nos anos da Guerra Fria em que o bloco formado pelos países capitalistas ocidentais apegou-se a aspectos formais dos direitos da pessoa, enquanto o bloco dos países socialistas concedeu maior atenção aos direitos dos povos (PALAZZO, 1998).

Evidenciamos, então, uma série de idéias sobre os direitos humanos, intimamente vinculadas ao pensamento liberal e aos preceitos do individualismo. Tratase de um fundamento de humanidade naturalizado que se confunde com o sentimento de propriedade e que, facilmente, bane de seu ângulo de visão os segmentos marginalizados e pauperizados, os "desviantes" e os miseráveis. Trata-se, ainda, de uma perspectiva de universalidade fundamentada no paradoxo de um "para todos", desde que incluído num determinado raio de visão, já que a lógica dos binarismos compromete a conquista de uma efetiva universalidade. Vê-se, então, uma lógica de universal contraposta à expressão da singularidade.

Assim, colocando o cerne dessa discussão na prerrogativa de que a solidariedade deve prevalecer sobre a defesa dos indivíduos, tornaram-se centrais, no debate sobre os direitos humanos, as noções de individualidade e de universalidade, marcando a luta por tais direitos desde o século XVIII e definindo a própria noção de humano. Noção essa fortemente vinculada à existência de uma essência humana e a uma necessidade de delimitação entre o eu e o outro, o meu e o teu, o próprio e o impróprio (COIMBRA; PASSOS; BENEVIDES, 2002). 
No entanto, se pensamos os direitos humanos por uma perspectiva temporalizada, na linha de um rizoma temporal, conforme propõe Pál Pelbart (1996), defendê-los torna-se uma luta pela multiplicidade, pelo diverso em todos e em cada um, rompendo com uma necessidade de "arranjo" do mundo em blocos de oposição. Em lugar de tomar os direitos humanos pautados pela noção de indivíduo, trata-se de defini-los como defesa ativa dos processos de "individuação", concebendo este último como processo ontogenético de diferenciação.

Assim, o caminho da defesa pelos direitos humanos afirma-se na luta pelos processos de diferenciação que dão passagem à vida, àquilo que não foi visto ou dito. Trata-se de viajar da identidade à multiplicidade, da posição ao potencial, do ser ao devir, enfim, do plano molar ao micropolítico.

A questão da universalidade dos direitos humanos ganha, então, outro sentido. Conforme Coimbra, Passos e Benevides (2002), em lugar de pensarmos no princípio da universalidade como estando vinculado ao homem como fundamento absoluto, essência ou natureza, vale pensarmos em um processo de universalização do compromisso com a vida, ou seja, pela construção de um ideal comum da humanidade na defesa da vida. Para os autores:

A questão da universalidade dos direitos humanos ganha, portanto, um outro sentido, dizendo respeito menos a uma universalidade do homem e mais à possibilidade de mobilização ou implicação dos diferentes homens na luta pela criação e preservação das diferentes manifestações da vida humana (COIMBRA; PASSOS; BENEVIDES, 2002, p. 17).

Trata-se de operar no terreno de uma política vinculada ao desenvolvimento expansivo da subjetividade, ou seja, ao modo como a vivência dos sujeitos pode se transformar incessantemente além dos limites rígidos impostos pelas pretensões identitárias.

\section{Ética E direitos humanos: Desafios PaRa A PRODUÇão de CONHECIMENTo}

Refletir sobre ética e direitos humanos enquanto desafios "para" e "na" produção do conhecimento pela transversalização do tempo e da subjetividade, coloca de imediato alguns questionamentos para pesquisadores e extensionistas, sobretudo no campo das Ciências Humanas e Sociais: até que ponto estamos sensíveis aos processos de singularização/individuação presentes no campo social, voltando-nos para eles em nossos projetos de trabalho? Estamos nós tomando a produção de conhecimento como prática, ou seja, problematizando a perspectiva de que nossas teorias expressam e traduzem verdades possuindo um caráter "revelador" da realidade, para, ao contrário, afirmá-las como produtoras do real?

Este me parece o ponto crucial da questão, uma vez que tangencia a dimensão das epistemologias, conforme anunciei anteriormente, ultrapassando o plano das normas e regras definidoras do ético ou do "não-ético" em projetos de pesquisa e extensão. Parece-me que o desafio maior reside nas amarras de nosso pensamento 
que, fortemente influenciado pelo projeto racional da modernidade, muitas vezes insiste em obstruir-se ao Fora, possibilidade pela qual se implode o raciocínio binário que sustenta a cisão entre sujeito e objeto, entre verdadeiro e falso. Nesse sentido, contribui Pál Pelbart (1998) quando diz que pensar o tempo crônico e não-cronológico, à mercê de sua força mais do que de sua forma, já não pode deixar intacta a noção de verdade, pois há uma potência do falso se afirmando como criadora.

No rastro do questionamento de Foucault (1979) de que o papel do intelectual é antes de tudo o de lutar contra as formas de poder, exatamente onde ele é, ao mesmo tempo, o objeto e o instrumento: na ordem do saber, da verdade, da consciência, do discurso, temporalizar a produção do conhecimento aparece como um instigante caminho para dar passagem àquilo que não se encontra nessa ordem, liberando o fluxo do que não foi figurado ou substancializado, libertando as potências do pensamento que estão presas e enclausuradas no feixe das configurações tradicionais.

Assim, a produção do conhecimento consiste mais em promover dessubstancializações e outras figurações, para fazer emergir novas formas de mundo e de viver, do que em buscar correspondências entre fatos e explicações. Trata-se mais de partilha do que de interpretação, de uma perspectiva rizomática em lugar de uma lógica representacional. Trata-se de entrar no acontecimento, conectando com as linhas a-significantes e impessoais para inventar, em lugar de buscar origens, já que o antes não é passado, é campo de imanência.

Pesquisar e fazer extensão eticamente e promovendo o direito à vida implica o pesquisador e/ou extensionista aceitar-se como corpo de passagem; em devir, cedendo lugar à experimentação, ou seja, à possibilidade de diferir de si mesmo e estimulando uma cognição que seja capaz de acionar a diferença em cada um. Valendo-se da intuição como método, trata-se de conectar com um campo de pulsações, procurando olhar perceptivamente as forças do Fora, aberto à afecção e à reflexão da afecção, produzindo sentido por elas, produzindo um Fora e um si mesmo.

Tomando o tempo como simultaneidade contraída, ex(pli)car consiste em desdobrar, estender o que está com( $p l i)$ cado, mergulhar não no tempo que passa e sim no tempo que dura, implicando-se nele para cartografar, isto é, para desmanchar, desfigurar, produzir outros sentidos, virtualizar o que está para ser inventado, produzir o que ainda não teve lugar no pensamento, dar passagem ao que ainda não foi visto nem dito. A idéia é devolver nossos "objetos" ao tempo complicado para remetê-los ao extratexto, ao imperceptível através da implicação, conectando com aquilo que não é dado aos sentidos e sim à sensibilidade.

Assim, nosso desafio, enquanto promoção da ética e dos direitos humanos pela produção de conhecimento, passa pela sustentação de um "não-discurso", considerando o discurso conforme Foucault (1979), isto é, enquanto prática que "conforma" os objetos de que fala. Significa perseguir as nãocorrespondências entre respostas e questões, procurando bifurcá-las, conforme propõe Deleuze (1998). Para o autor: "Se não deixam que você fabrique suas questões, com elementos vindos de toda a parte, de qualquer lugar, se as 
colocam a você, não tem muito o que dizer. [...] O objetivo não é responder a questões, é sair delas" (DELEUZE, 1998, p. 9).

Deleuze incita, portanto, a pensar que produzir conhecimento, a partir da formulação de problemas, implica bifurcar de si mesmo, bem como bifurcar suas próprias questões. Isto é, implica "outrar-se" pela experimentação, bem como (des)ajustar as respostas de suas questões.

Propondo que conectemos com os devires, os quais são silenciosos e quase imperceptíveis, jamais imitáveis nem ajustáveis a um modelo ou conceito, uma "inconfidência sem interlocutor possível” (DELEUZE, 1998, p.11), defende a posição de que não há nada a compreender, nada a interpretar, sendo necessário traçar linhas de fuga para o que é "estranho", para o que não tem correspondência, para o que escapa e que, por escapar, é a materialização mesma das forças que transformam.

Desse modo, a tarefa de pesquisar e de fazer extensão não passa, portanto, por nenhum método ou por metodologia que leve ao (re)conhecimento, pois reconhecer é o contrário do encontro. Passa, outrossim, pela tensão entre a captura e a fuga, pelo engano, pelo erro. Passa pela virtualização de uma ciência nômade e fugidia.

\section{Notas}

1 Discutindo o comportamento humano nas áreas das ciências da vida e dos cuidados da saúde, tal perspectiva assenta-se no tripé: profissional/técnico (pela beneficência); paciente/pesquisado (pela autonomia); e social (pela justiça). Fala-se, ainda, em Bioética de Fronteira, voltada para a fase nascente e para a fase terminal da vida, e em Bioética Cotidiana, voltada para a exigência de humanização das técnicas e dos métodos em saúde (CONSELHO REGIONAL DE PSICOLOGIA, 2002).

2 Por Ética da conexão a autora entende as práticas que transformam os corpos em território de ressonâncias, repudiando a todo o autismo e a pretensão de colocar o próprio corpo no começo e no fim dos processos. Propõe fugir para o meio, onde se dão as lutas, as disputas, a criatividade. Ao contrário do corpo totalitário, destituído da diferença, afirma o elo entre os corpos, pois na finitude da existência do corpo ressoaria a infinita potência criadora do mundo.

3 Para Deleuze e Guattari (1995, p. 25 c 37), um sistema de subtração do único na multiplicidade a ser constituída poderia ser chamado de rizoma. "Ser rizomorfo é produzir frases e filamentos que parecem raízes, ou, melhor ainda, que se conectam com elas penetrando no tronco, podendo fazêlas servir a novos e estranhos usos". "Um rizoma não começa nem conclui, ele se encontra sempre no meio, entre as coisas, inter-ser, intermezzo".

4 O Fora, segundo Pál Pelbart (1999), é abertura de um futuro, apresenta-se como o "espaço" no qual nada acaba, porque nada começou e tudo se metamorfoseia. Para Deleuze (1988) trata-se de "uma matéria móvel animada de movimentos peristálticos, de dobras e pregas (plis e plissements) que constituem um dentro: não outra coisa que o Fora, mas exatamente o dentro do Fora".

5 Para Deleuze (1998, p.11) "os devires são o mais imperceptível, são atos que só podem estar contidos em uma vida e expressos em um estilo". Eles não são imitáveis nem ajustáveis a um modelo, tratando-se de algo que opera por "dupla captura", como um encontro em que os "uns" afetam-se numa zona fora deles, deixando de ser o que são para "outrarem-se". 


\section{REFERÊNCIAS}

CHAUÍ, M. Convite à Filosofia. São Paulo: Brasiliense, 1995.

COIMBRA, C.; PASSOS, E.; BENEVIDES, R. Direitos Humanos no Brasil e o Grupo Tortura Nunca Mais/RJ. In: Clínica e Política: Subjetividade e Violação dos Direitos Humanos. Rio de Janeiro: Te Corá/Instituto Franco Baságlia, 2002.

CONSELHO REGIONAL DE PSICOLOGIA, 17., 2002, Porto Alegre. Entre Linhas. Publicação do Conselho Regional de Psicologia. Porto Alegre: RGS, 2002. DELEUZE, G. Foucault. São Paulo: Brasiliense, 1998.

A Imanência: uma vida. Educação e Realidade, Porto Alegre, v. 27, n. 2, p. 10-18, jul./dez. 2002.

DELEUZE, G.; GUATTARI, F. Mil Platôs: Capitalismo e Esquizofrenia. Rio de Janeiro: Ed. 34, 1995.

FOUCAULT, M. Microfísica do Poder. Rio de Janeiro: Graal, 1979.

PALAZZO, L.O. A Evolução dos Direitos Humanos e suas Novas Dimensões. In:___ Psicologia, Ética e Direitos Humanos. Brasília: Conselhos Federais de Psicologia, 1998.

PELBART, P. P. Rizoma Temporal. Educação, Subjetividade e Poder, Porto Alegre, v. 5, n. 5, p. 60-63. jul. 1996.

. O Tempo Não-Reconciliado. São Paulo: Perspectiva: FAPESP, 1998.

. Da Clausura do Fora ao Fora da Clausura: Loucura e Desrazão.

São Paulo: Brasiliense, 1999.

SANT'ANNA, D. B. de. Corpos de Passagem: ensaios sobre a subjetividade contemporânea. São Paulo: Estação Liberdade, 2001.

SIMONDON, G. l'Individu et sa Genèse Physico-Biologique. Boulevard Saint Germain: Paris VI - Presses Universitaires de France, 1964.

Recebido em: outubro / 2004.

Aceito em: julho / 2005. 